To the Editors:

\title{
Thyroid volume in a cohort of Sri Lankan patients: a preliminary report
}

Thyroid volume varies in different populations [1]. This is influenced by environmental factors such as deficiency of iodine and genetic factors [2]. Sri Lanka is considered to be endemically deficient in iodine. This is likely to influence the thyroid size in Sri Lankans. Clinical palpation has low sensitivity [3]. Hence ultrasound scan is the investigation of choice. This study envisages a more accurate assessment of thyroid volume using an ultrasound scan and developing a reference value for thyroid volume.

In-ward patients receiving treatment in the university surgical unit for problems other than thyroid disorders and their bystanders were assessed with a proforma to select individuals for the study. Pregnant or lactating women, ill patients, children below 16 years, those with abnormalities on ultrasound examination and suspicious thyroid status were excluded. Informed written consent was taken. Thyroid scan was done by a consultant radiologist using a $7.5 \mathrm{MHz}$ linear probe. Participants were selected randomly using lottery method (simple random sampling) from all individuals eligible for the study. Thyroid volume was assessed using the ellipsoid formula [(xx yxzx0.524) x- transverse diameter, y-sagital diameter, zantero-posterior diameter]. Sum of volumes of both lobes were considered as thyroid volume. Sample size was determined using a pilot study. A sample of 60 males and 30 females were required. Statistical calculation was done using SPSS software package. Student's t test was used to compare means. Correlation between thyroid volume and age, height and BMI were assessed using Pearson correlation coefficient. Approval for the study was obtained from Ethics Review Committee, Faculty of Medicine, Kelaniya

Sixty males with mean age of 33 years and 30 females with median age of 42 years were assessed. Mean thyroid volume of males was $8.628 \mathrm{ml}$ (range-2.657-15.15). Mean thyroid volume of females was $6.413 \mathrm{ml}$ (range-2.871-9.717). Table 1 shows demographic (mean) data and mean thyroid volume of sample. This difference was statistically significant $(p<0.01)$. Overall thyroid volume was $7.889 \mathrm{ml}$ (2.745). There was no significant difference in volume of both lobes. There was no significant correlation with height weight or BMI. Reference range [mean +2 standard deviations (SD)] for males and females were 8.628 \pm 5.46 $\mathrm{ml}$ and $6.413 \pm 3.32 \mathrm{ml}$ respectively.
Table 1

\begin{tabular}{lcccc}
\hline & $\begin{array}{c}\text { Age } \\
\text { (years) }\end{array}$ & Height & BMI & $\begin{array}{c}\text { TV } \\
(\mathrm{SD})\end{array}$ \\
\hline All & 36 & 162.4 & 21.29 & $7.889(2.74)$ \\
Males & 33 & 166.22 & 20.54 & $8.628(2.73)$ \\
Females & 42 & 154.9 & 22.79 & $6.413(1.66)$ \\
\hline
\end{tabular}

Males have significantly higher thyroid volume than females, as supported by other studies. This may be explained by larger body frame of males [1, 2, 4]. Significant correlation between thyroid volume and height, age were demonstrated by other studies [5]. This study did not show any correlation with age, height or BMI. Thyroid volume $(7.7 \pm 3.3 \mathrm{ml})$ closer to values of this study has been reported from China [5]. This may be explained by similar height of Chinese to Sri Lankans. Some western countries have reported higher thyroid volumes [1]. Sample size in this study is small and hospital based. This study is a preliminary study. A large scale communitybased study is envisaged.

\section{References}

1. Gomez JM, Maravall FJ, Gomez N, Guma A, Soler J. Determinants of thyroid volume as measured by ultrasonography in healthy adults randomly selected. Clinics Endocrinology (Oxf) 2000; 53: 629-34.

2. Hegedus L, Perrild H, Poulsen LR, Anderson J, et al. The determination of thyroid volume by ultrasound and it's relationship to body weight, age, sex in normal subjects. Journal of Endocrinology and Metabolism 1983; 56: 260-3.

3. Ahidjo A, Tahir A, Tukur M. Ultrasound determination of thyroid gland volume among adult Nigerians. The Internet Journal of Radiology 2006; 4.

4. Glutekunst R, Smolarek, Hasenpusch U, et al. Goitre epidemiology: thyroid volume, iodine excretion, thyroglobulin in Germany and Sweden. Acta Endocrinology 1986; 112: $494-501$.

5. Adibi A, Sious M, Roohi E, et al. Normal values of thyroid gland in Isfahan, an iodine replete area. Journal of Research in Medical Sciences 2008; 13: 55-60.

\section{R Fernando ${ }^{1}$, D M S M Bandara ${ }^{1}$, A de Silva ${ }^{2}$, M D S Renuka ${ }^{1}$, N Atulugama $^{1}$ \\ ${ }^{1}$ Department of Surgery, University of Kelaniya, Sri Lanka and ${ }^{2}$ Department of Radiology, North Colombo Teaching Hospital, Sri Lanka.}

Correspondence: RF, e-mail <ranilfern@sltnet.lk>. Received 6 November 2009 and revised version accepted 5 March 2010. Competing interests: none declared. 